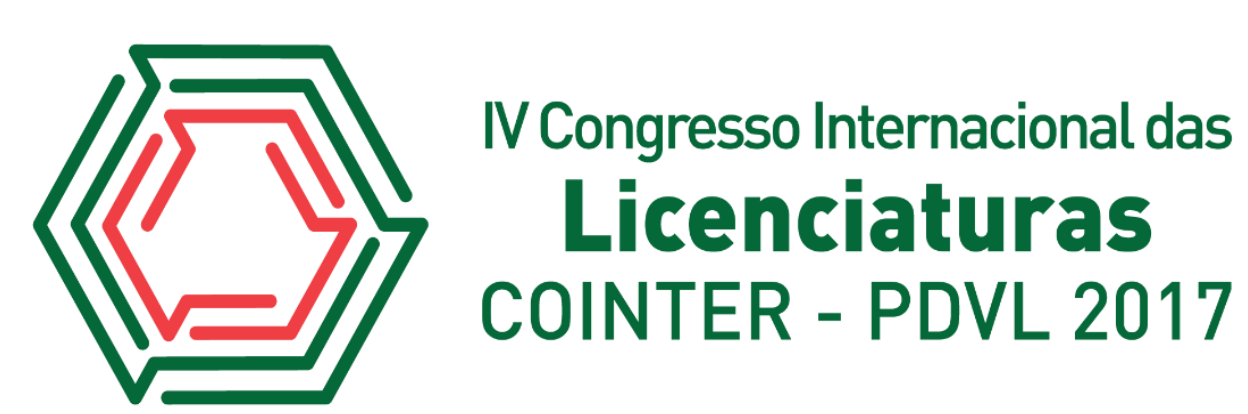

\title{
UM ESTUDO DA VIOLÊNCIA NA ESCOLA MUNICIPAL FRANCISCA FERREIRA (NATAL/RN/BR)
}

Apresentação: Comunicação Oral

\author{
Jerônimo Freire \\ Escola Municipal Francisca Ferreira - UNINASSAU \\ jeronimofreire@hotmail.com. \\ Ianna Carla Almeida da Silva \\ Escola Municipal Francisca Ferreira - CCHLA / UFRN \\ iannaufrn@gmail.com
}

\section{RESUMO}

Este trabalho apresenta o resultado de uma pesquisa realizada na Escola Municipal Francisca Ferreira, na região oeste da Cidade de Natal/RN/Brasil, com o propósito de diagnosticar a violência dentro e fora da escola, especificamente na sua vizinhança. Foi aplicado um Questionário (Formulário Google) para uma amostragem de 100 estudantes do Ensino Fundamental II, adolescentes na faixa de idade de 10 aos 15 anos. A apresentação e a discussão dos dados empíricos foram analisadas abordando as situações de violências e proposto ações socioeducativas para se criar uma conscientização pela cultura de paz. Neste estudo, consta-se que o ambiente educacional na instituição tem sido vítima da violência que vem em sua maioria das redondezas, nos contornos da escola e isto tem implicações no processo de ensino e aprendizagem da comunidade escolar.

Palavras-chave: Políticas Públicas; Políticas Educacionais; Violências nas escolas;

Jerônimo Freire é físico, mestre em ciências dos materiais e doutorando em Educação (PPGED/UFRN).

Ianna Carla Almeida da Silva é pedagoga, professora da Escola Municipal Francisca Ferreira (Natal/RN/Brasil). Aluna do curso de letras do CCHLA / UFRN 


\section{1 - Introdução.}

As diversas manifestações das violências nas escolas não se constituem fato ou fenômeno novo. Na história da educação são relatadas diferentes formas de violências, inclusive as perpetradas pela escola, por intermédio dos castigos e punições (esta não é objeto de estudo do presente trabalho, mesmo porque não é rotina da escola utilizar desses meios na sua prática pedagógica). Neste trabalho, o centro das atenções, está no diagnóstico da violência. De onde elas vêm? Da escola? Das condições sociais e morais em que são socializadas fora das escolas? Poderiam ter sido evitadas? Temos poder de evitá-las? Quais as práticas pedagógicas a serem utilizadas para contribuir com uma conscientização pela cultura de paz? Estas são indagações que este trabalho tem como objetivo responder a luz da literatura, tendo como espelho outras pesquisas feitas pela UNESCO, e localmente avaliando com base nas respostas dada pelo formulário em questão.

O que é caracterizado como violência escolar varia em função do estabelecimento, de quem fala (professores, diretores, alunos etc.), da idade e provavelmente do sexo. Não existe consenso em torno do seu significado. O conceito de violência escolar citado na literatura, pode ser visto em diversas situações: (1) situações que ocorrem dentro da estrutura física da escola, mas também no trajeto casa-escola e em festas e visitas escolares, (2) pode ocorrer entre alunos, mas também entre alunos e professores/funcionários, pais de alunos e alunos e pais de alunos e professores/funcionários, (3) pode ser subdividida em violência física, emocional, sexual, patrimonial e negligência ou subdividida em violência direta (física, patrimonial ou sexual) ou violência indireta (emocional), (4) a violência também pode ser institucional, por meio das práticas, regras e normas implícitas da própria instituição, (5) há aspectos mais específicos do problema, recebendo atenção especial, como o bullying, (6) o porte de armas, o tráfico e abuso de drogas lícitas e ilícitas também fazem parte do conceito. Os termos para indicar a violência também variam de um país para outro. Nos Estados Unidos, diversas pesquisas usam delinquência juvenil. Na Inglaterra, alguns autores defendem que o termo violência na escola só seja empregado no caso de conflito entre estudantes e professores ou em relação a atividades que causem suspensão, atos disciplinares e prisão (3).

\section{A Escola Municipal Francisca Ferreira e a sua comunidade.}

A Escola Municipal Professora Francisca Ferreira da Silva está localizada na Avenida Industrial João Francisco da Motta, no 3804, Bairro Bom Pastor, Zona Oeste de Natal, Estado do Rio Grande do Norte sendo uma referência no Bairro Bom Pastor por se destacar em termos de estrutura física com amplo espaço socioeducativo que visa atender as demandas educativas da comunidade. Como unidade de ensino vinculada a Prefeitura Municipal de Natal está subordinada a Secretaria Municipal de Educação e se orienta pela legislação vigente do Sistema Nacional e Municipal de Ensino, sendo inaugurada no dia 31 de maio do ano de 1978 através do Decreto Lei $\mathrm{n}^{\circ}$ 2.055/76 e Portaria de $\mathrm{n}^{\circ}$ 078/96. Funcionando inicialmente num prédio cedido pela Empresa Frigorífica do Rio Grande do Norte (Ex-FRIGONARTE), anexa ao referido Órgão, apresentava instalações impróprias para o porte de uma unidade escolar, surgindo como proposta de ofertar ensino aos filhos dos funcionários para minimizar a escassez de escolas. A demanda de alunos que procuravam a instituição promoveu uma expansão da oferta de ensino durante o período de 1978 a 2002, impulsionando a escola a implantar no ano 
de 1981 alguns anexos em casas ou prédios alugados pela Prefeitura Municipal de Natal, formando um complexo espaço escolar. O longo processo de expectativa para conquista de um prédio escolar (próprio), que correspondessem em termos de estruturas física e material, mas principalmente coerente com o desenvolvimento das atividades de ensino, provocou várias mobilizações políticas com a comunidade do Bairro, reivindicando um espaço institucional que oferecesse um ambiente mais adequado as necessidades profissionais de seus funcionários, e em particular, as formativas dos alunos. A inauguração da sede própria ocorre no dia 10/03/2003, coincidindo com o evento dos 25 anos de fundação, contando com a presença de várias autoridades municipais e estaduais. Foram mais de 20 anos de criação para que a Prefeitura de Natal construísse de fato, a Escola Municipal Francisca Ferreira da Silva, que passou a contar com uma excelente estrutura física composta por amplos ambientes assim distribuídos: 10 salas de aulas, 01 biblioteca, 01 sala de vídeo, 01 sala de informática, 01 sala de diretoria, 01 sala para equipe técnica, 01 sala de professores, 01 secretaria, 01 cozinha com dispensa, 01 quadra de esportes, 03 banheiros p/ os profissionais, 02 banheiros coletivos para os alunos, 02 salas de arquivos para expediente da secretaria, 02 arquivos para materiais de serviços, 01 refeitório, 01 pátio recreativo e estacionamento. A concretização de um ambiente escolar favorável atendeu as históricas reivindicações da comunidade que buscavam realizar uma proposta de trabalho proativa, embora alguns desafios em atender a clientela em termos de serviço educativo e de ensino ainda permaneça.

\title{
3 - As implicações da violência na educação.
}

O estudo da violência na Educação, na realidade passa por uma profunda análise relacionada aos aspectos conceituais, legais, pedagógicos, psicológicos, sociais, culturais, históricos, entre outros, visto que se trata de um fenômeno de muita complexidade (1). O conceito de violência também deve ser pensado como algo criado social e historicamente, fruto de discursos de um determinado período. O que hoje conceituamos como violência nem sempre foi visto como tal (2), o que nos habilita a afirmar que a temática da(s) violência(s) contra crianças e adolescentes pode ser vista como construção social (3). Isso nos leva a refletir que nem sempre o que na atualidade consideramos formas de violência, especialmente contra crianças e adolescentes, em outras épocas, seria tido como tal, especialmente porque nem sempre a criança/adolescente foi vista como sujeito de direitos.

\author{
"Todas as pessoas nascem livres e iguais em \\ dignidade e direitos", proclama o artigo primeiro \\ da Declaração Universal dos Direitos Humanos
} (4).

\section{4 - Resultados e discussão da Pesquisa}

\section{1 - A Metodologia.}

A coleta dos dados teve como método a observação direta, com questionários (formulário Google) empregados como instrumentos de pesquisa em formato Online e impresso. Em maio de 2016 teve o início a aplicação dos Questionários. Nesta ocasião foi 
entregue para o preenchimento o questionário aos alunos que ficaram à vontade para participar ou não da pesquisa. Dessa forma, dentre os que se mostraram interessados destaca-se uma amostra aleatória simples de aproximadamente $30 \%$ dos estudantes matriculados no Ensino Fundamental II da Escola Municipal Francisca Ferreira (100 participantes), com participação de estudantes do turno da tarde (a maioria) e noite.

\section{2 - Apresentação dos Resultados.}

A Estatística Descritiva tratada neste trabalho se constitui num conjunto de técnicas que objetivam descrever, analisar e interpretar os dados numéricos de uma população ou amostra. Neste trabalho são apresentados 3 blocos de Perguntas relacionadas aos dados percentuais obtidos da amostra e logo em seguida uma breve interpretação dos resultados que representam, de maneira sintética, as informações sobre o comportamento das variáveis numéricas levantadas através do processo de pesquisa. A pesquisa foi realizada no segundo semestre de 2016, com a participação de professores, estudantes e funcionários

Do Bloco A de Perguntas. Os resultados obtidos nos dados de identificacão (A1) dos estudantes permitem verificar que 53,3\% dos participantes são do sexo feminino, ao passo que, $46,7 \%$ dos mesmos são do sexo masculino. No que diz respeito a faixa de Idade (A2), constatase que quase a metade dos entrevistados (46,7\%) estão na faixa dos 13 aos 15 anos, e o restante estão divididos com 26,7\% respectivamente para as faixas de idade entre 11 e 13 anos e acima de 16 anos.

\section{A 1 - Qual a sua faixa de idade?}

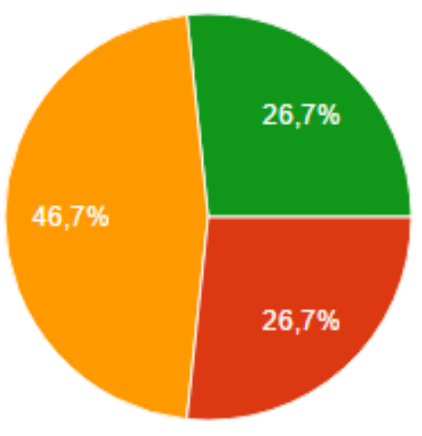

Dos 8 aos 10 anos.

Dos 11 aos 13 anos.

Dos 13 aos 15 anos.

Acima dos 16 anos.

\section{A 2 - Qual o seu sexo}

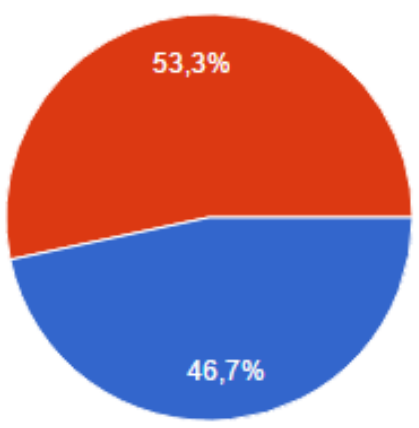

Masculino

Feminino 
As questões de violência relacionadas a vizinhança da escola, evidenciam percentuais de que o estudo da violência na escola tem que levar em consideração os fatores próximos a instituição. As questões A4, A6, A7 e A8, demonstram que a violência é vista no contorno da escola (agressão verbal, vandalismo, roubo ou assalto e principalmente uso de drogas), e que suas causas são decorrentes principalmente pelo uso de drogas e falta de policiamento. O dado mais significativo deste bloco, é de que mais da metade $(53,3 \%)$ se acham inseguros no trajeto da casa/escola e escola/casa. Levando-se em consideração de que $91 \%$ dos estudantes vão para escola e retornam a pé (A3) para casa, os percentuais atribuídos as questões da violência acenam para que medidas sejam pensadas para evitar problemas futuros.

\section{A 4 - Você se sente seguro no trajeto da sua casa para escola / da escola para sua casa?}

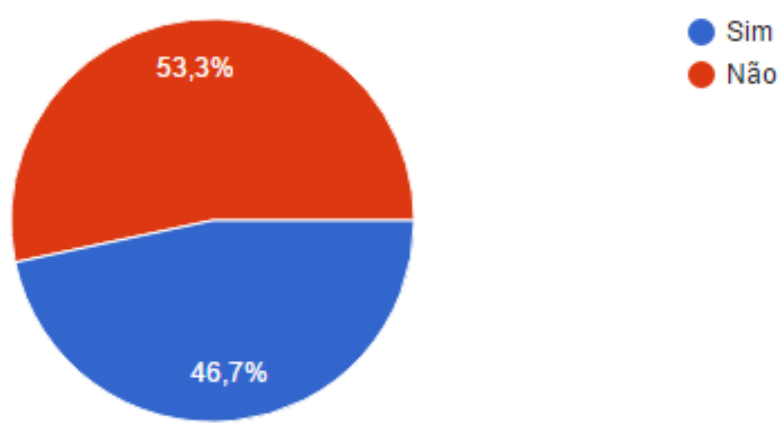

\section{A 6 - Qual das formas de violência abaixo você observa (ou tem conhecimento em sua comunidade) "fora dos muros" da escola? "Você pode marcar mais de uma opção"}

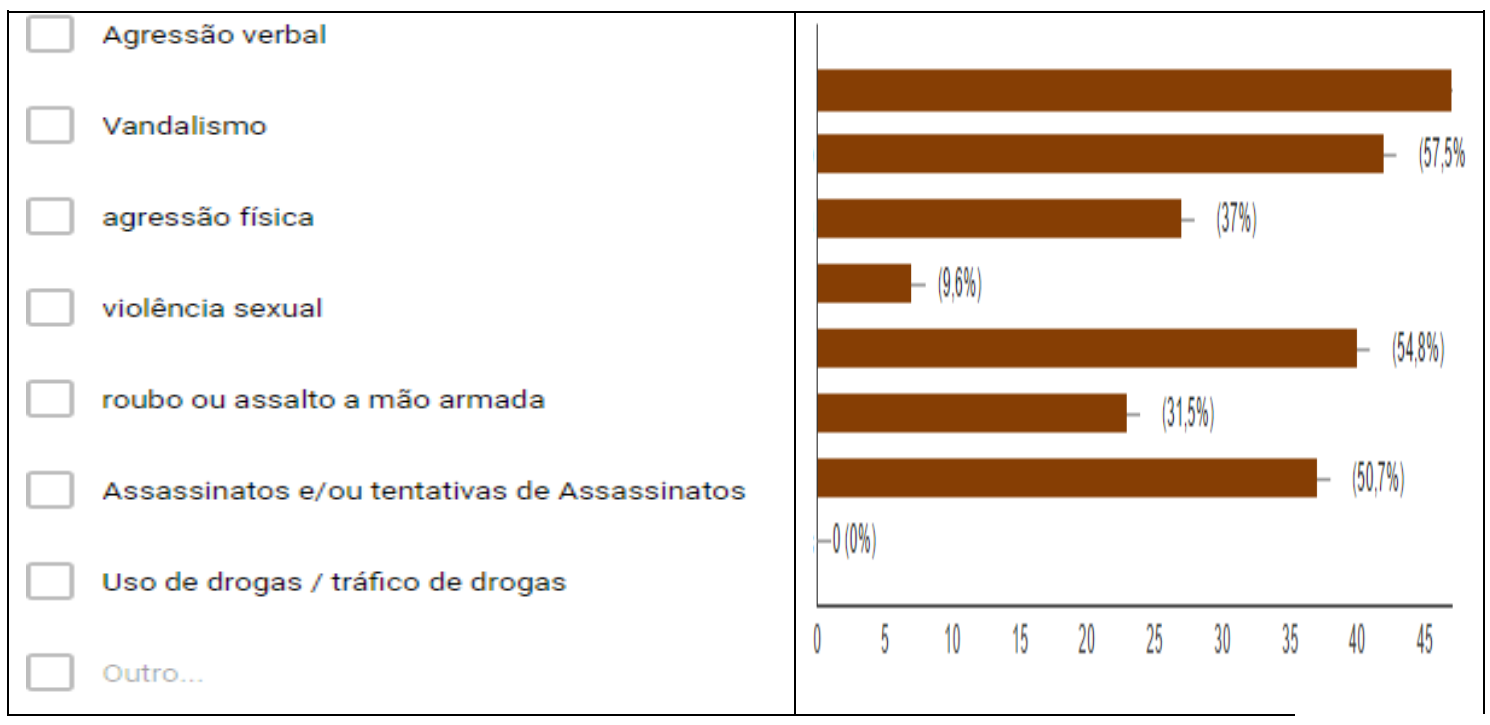

No bloco B, especificamente nas questões (B1, B13), observamos que as respostas dos participantes do estudo empírico indicam as agressões físicas e verbais como sendo as principais formas de manifestações das violências, confirmando estudos e resultados de outras pesquisas de que o bullying é responsável na maioria dos casos das violências no interior das instituições de ensino (3). 
B 1 - Você observa no dia-a-dia da sua escola comportamentos agressivos, intencionais e repetitivos, adotados por um ou mais colegas, contra outro(s) em desvantagem de poder ou força física, sem motivação evidente, sob a forma de "brincadeiras" que disfarçam o propósito de maltratar e intimidar, causando dor, angústia e sofrimento.

\section{(75 respostas)}

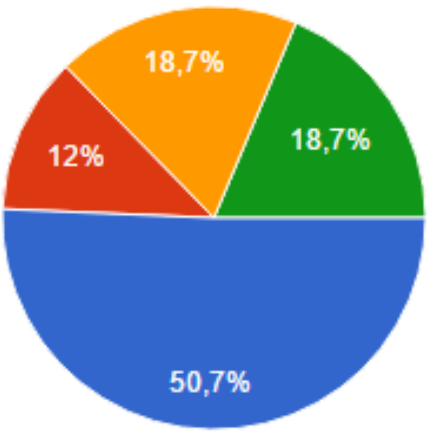

Sim

Frequentemente

Raramente

Não

B 13 - Em sua opinião quem são os autores mais frequentes dos casos de violência na sua escola? "Você pode marcar mais de uma opção"

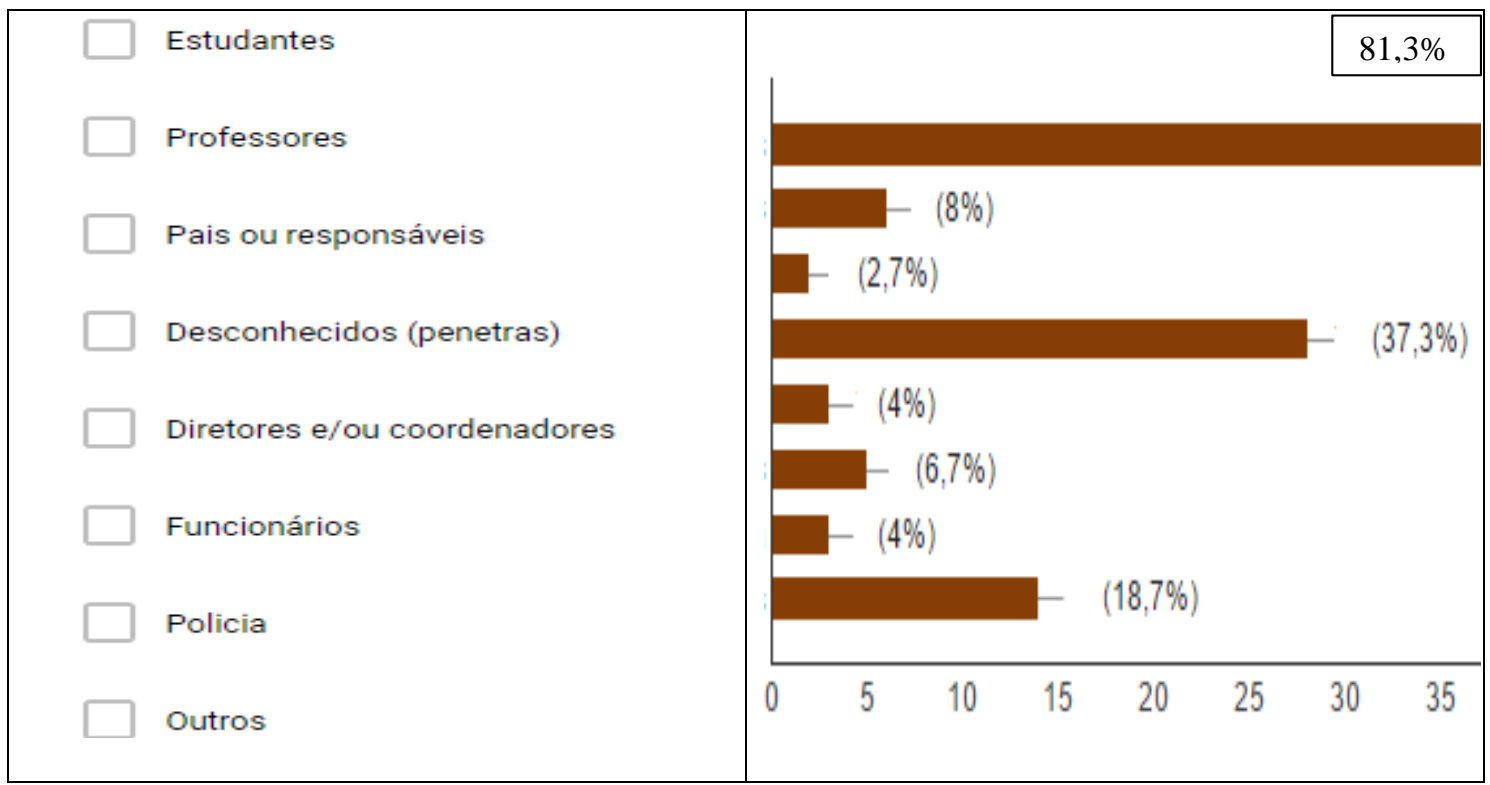

Infelizmente, as violências estão bem visíveis nos espaços escolares. Observando a Questão (B14), identificamos que os autores de tais atos de violência são os próprios estudantes, tirando da escola o cumprimento de sua finalidade educativa, como espaço de garantia e vivência de direitos. A principal causa nasce nos conflitos dos estudantes, importante notar que $30 \%$ dos participantes indica a falta de normas disciplinares mais rígidas por parte da gestão da escola como um dos motivos para estes atos de violência. 
B 14 - Na sua opinião qual/quais a(s) principal/principais causas da violência em sua escola? "Você pode marcar mais de uma opção"

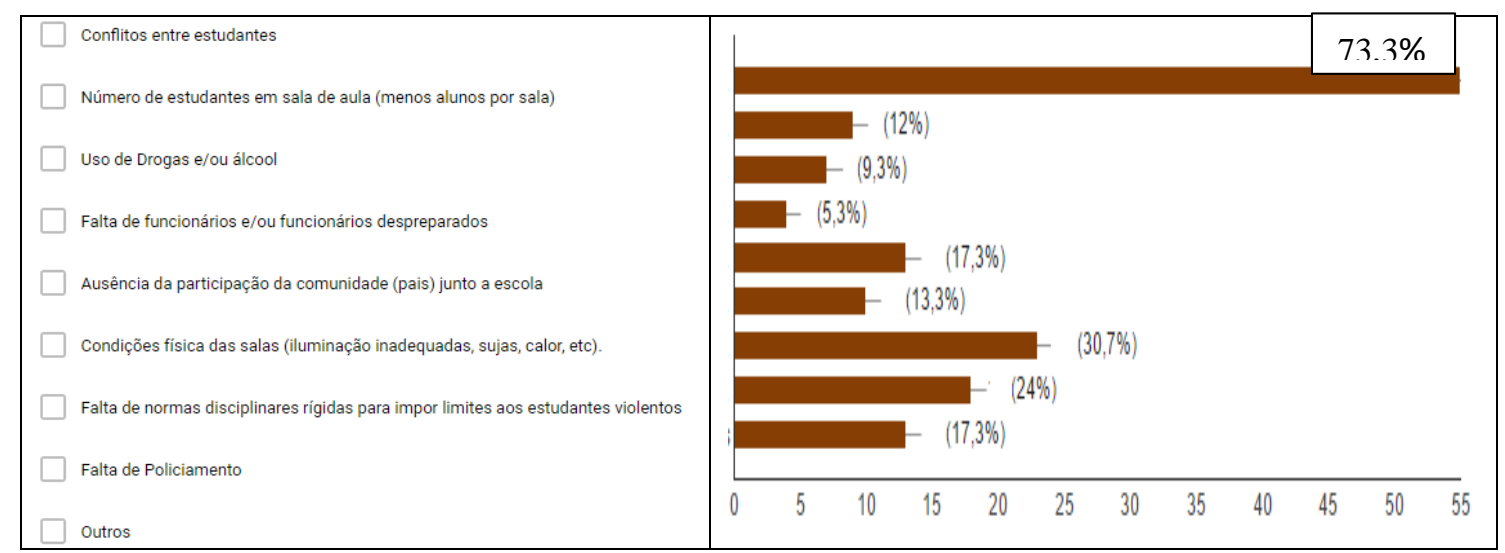

Outro ponto destacado na pesquisa, diz respeito às questões relacionadas ao porte de armas, roubos e furtos, o tráfico e abuso de drogas lícitas e ilícitas. As questões B2, B6, B7 e B9, apresentam dados significativos que comparado aos dados policiais do bairro passam ser preocupantes.

B 2 - Você já teve conhecimento de atos de violência dentro da sua escola no que diz respeito a furtos ou roubos?

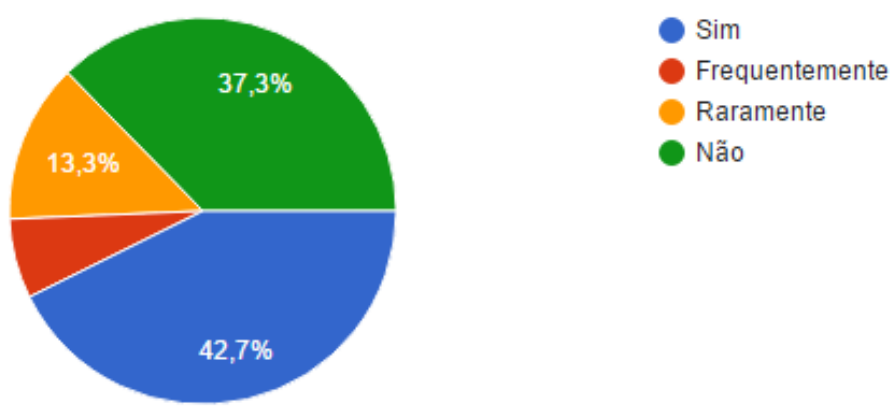

B 6 - Você tem conhecimento ou já viu estudantes com armas (revolver, faca, canivetes, soqueiras, etc) no interior da escola?

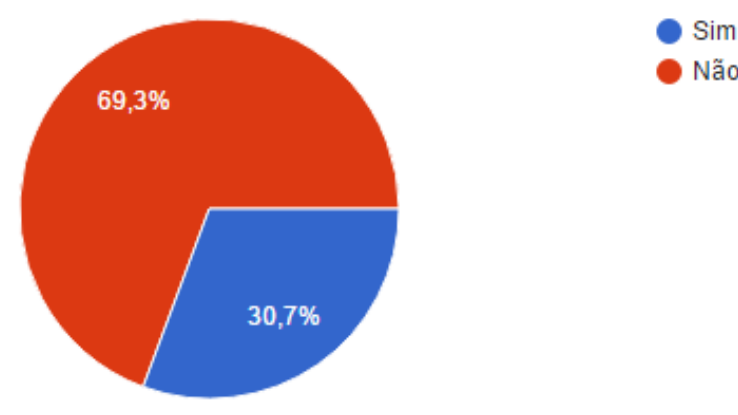


B 7 - Você já teve conhecimento ou presenciou consumo ou tráfico de drogas dentro de sua escola?

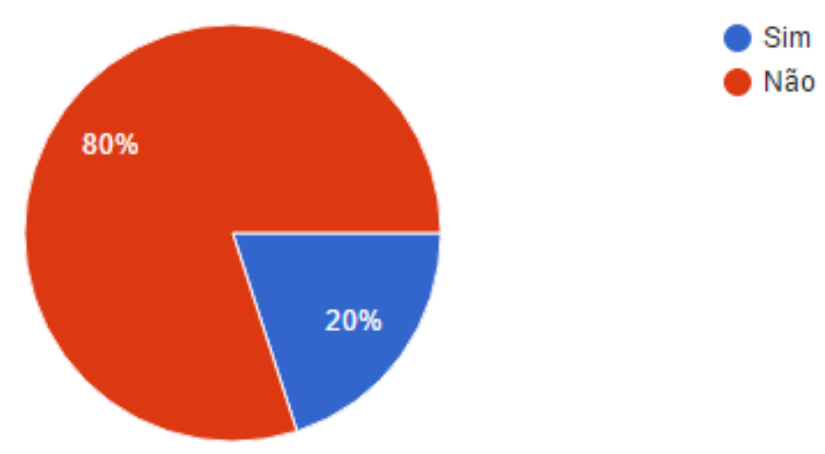

\section{B 9 - Você já sofreu roubo ou furto na escola?}

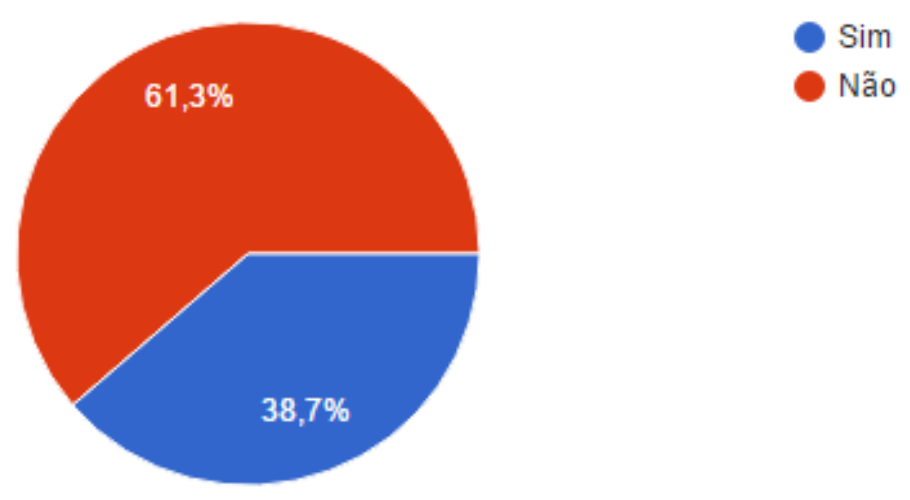

Observamos que os dados referentes as questões B2 e B9 apresentam percentuais bastante próximos, em torno de $40 \%$ para a violência referente ao roubo ou furto. Esse dado é significativo e preocupante para uma instituição de ensino. Os valores respectivos de $31 \%$ e $20 \%$ para violências de uso de armas e consumo de drogas chama a atenção e requer medidas urgentes para acalmar as famílias que tem seus filhos na escola.

O Bloco C de Perguntas analisa as opiniões propostas aos participantes quanto as ações futuras que eles desejam para minimizar os problemas da violência na escola. 

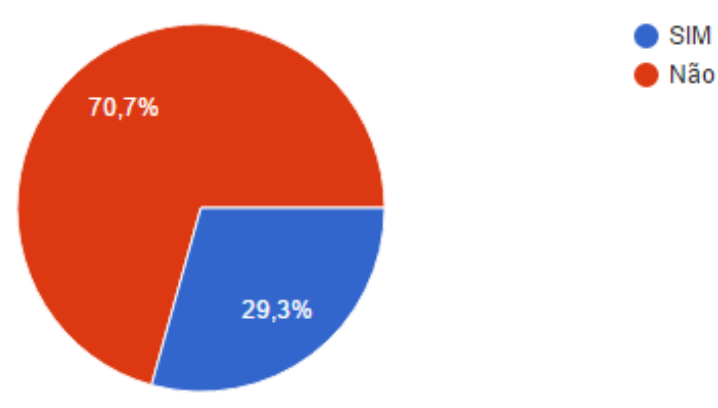

C 2 - Na sua opinião, a violência na sua escola, tem aumentado ano a ano?

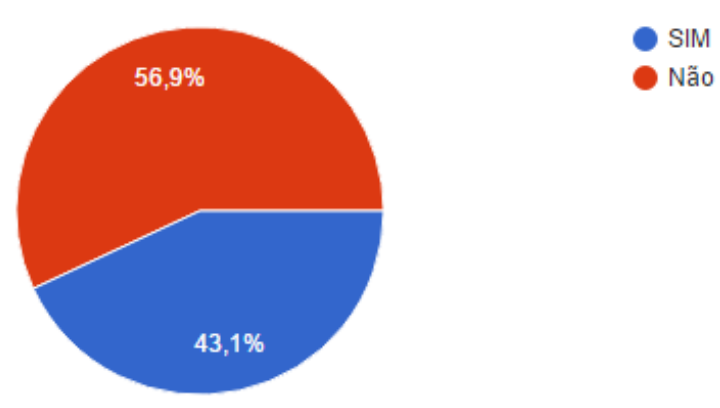

C 3 - Qual das medidas abaixo você considera ideal para diminuir os atos de violência em sua escola (casos de agressão física e verbal, vandalismo, drogas e álcool, etc)?

( ) Ação dos professores - Conversar com os responsáveis pelos alunos (pais, avós, tios, representantes legais).

( ) Ação da diretoria ou coordenação. Conversar com os responsáveis pelos alunos (pais, avós, tios, representantes legais). Registrar BO na delegacia e/ou encaminhar ao conselho tutelar.

( ) Ação de todos. Medidas preventivas, discutir no âmbito da escola ações que leve a não violência, instalar uma cultura de paz com a participação da comunidade.

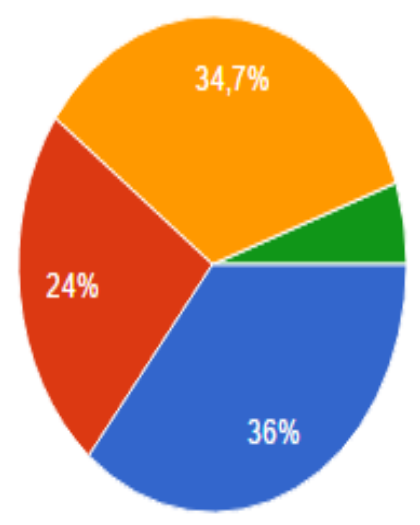

( ) Não tomar nenhuma medida. 
A Questão C4 apresenta diversas sugestões de atividades a serem organizadas e trabalhadas na Escola com o objetivo de discutir ações para uma conscientização pela cultura de paz. Observamos que as sugestões foram aceitas de forma uniforme, sendo a proposta de Reuniões com pais e responsáveis a que obteve o maior percentual $(41,4 \%)$. Esta opção somada a da questão C3, ação de todos (Medidas preventivas, discutir no âmbito da escola ações que leve a não violência, instalar uma cultura de paz com a participação da comunidade), demonstra o grande interesse dos discentes em atividades que possam colaborar com a diminuição da violência tanto na escola como em sua comunidade. Diante dos dados a equipe de professores junto a equipe pedagógica e gestora da Escola Municipal Francisca Ferreira pretende trabalhar o tema "Violência" contextualizando com os assuntos das disciplinas de cada Ano do Ensino Fundamental II, e espera com isso diminuir o percentual dos que tem conhecimento de um projeto de educação pela Paz e que a violência na escola possa diminuir ano-após-ano.

\section{5 - Considerações Finais.}

Torna-se fundamental a permanente atenção sobre a existência das violências nas escolas, via diagnósticos que permitam a compreensão das especificidades das dinâmicas dos sujeitos em cada contexto e, a partir daí a definição de estratégias de intervenção. O reconhecimento da existência e das suas possíveis configurações poderá deflagrar possíveis ações. Entretanto, o desconhecimento, a invisibilidade ou negação geram a inação, o que poderá agravar a violação de direitos no espaço escolar.

O estudo empírico, no qual ouvimos estudantes, professores, gestores, funcionários e pais, apresenta percepções bastante elucidativas para a compreensão do fenômeno nas escolas. De modo geral, os sujeitos que estão mais presentes e atuantes no cotidiano escolar afirmam que existem violências, embora as considerem poucas. Talvez, em virtude da frequência, as manifestações de violências passem aparência de normalidade, podendo adquirir invisibilidade aos olhos de muitos.

\section{6 - Conclusão}

Os estudos confirmam que as violências se evidenciam por intermédio de agressões e constrangimentos que podem ser: físicos - empurrões, cutucões, socos, pontapés, esbarrões; verbais - apelidos, deboches, ameaças; sociais - exclusão, isolamento, descaso; simbólicos desigualdades, preconceitos, discriminação, relações de poder, currículos hegemônicos, monoculturas e etnocêntricos. O vandalismo, ou seja, a violência contra o patrimônio e equipamentos públicos, é outro tipo de violência bastante presente no cotidiano escolar, que "embora não sejam dirigidas diretamente contra as pessoas, afetam os sujeitos na esfera individual e social". Avaliar de forma diagnostica a violência na Escola Municipal Francisca Ferreira é importante para o conhecimento da real dimensão do fenômeno e para que se possam planejar intervenções que diminuíam o problema. Além disso, avaliações precisas e confiáveis, possibilitam comparações de resultados entre escolas, diferentes regiões e épocas, como também podem identificar alunos que estejam em situação de risco, sejam como vítimas de violência escolar ou como autores. Neste estudo, consta-se que o ambiente educacional na instituição tem sido vítima da violência que vem em sua maioria das redondezas, nos contornos da escola e isto tem implicações no processo de ensino e aprendizagem da comunidade escolar. 


\section{REFERÊNCIAS BIBLIOGRÁFICAS.}

(1) Gomes, Roberto Alves, \& Martins, Angela Maria. (2016). Conflitos e indisciplina no contexto escolar: a normatização do Sistema de Proteção Escolar em São Paulo. Ensaio: Avaliação e Políticas Públicas em Educação, 24(90), 161178.https://dx.doi.org/10.1590/S0104-40362016000100007

(2) GONÇALVES, L.A.O. e SPOSITO, M. P. (2003) Iniciativas de Redução da Violência Escolar: o caso de São Paulo. Movimentos Sociais e Educação - GT 3. Disponível em: 〈http://www.anped.org.br/25/luizalbertogoncalvest03.rtf>. Acesso em: maio. 2016.

(3) CHAKUR, Gabriela de Sá Leite and OLIVEIRA, Maria Lúcia. Programas educativos e a violência na escola.. In: SIMPOSIO INTERNACIONAL DO ADOLESCENTE, 2., 2005, São Paulo. Proceedings online... Available from:

<http://www.proceedings.scielo.br/scielo.php?script=sci_arttext\&pid=MSC00000000 82005000200019\&lng=en\&nrm=abn>. Acess on: 28 May. 2016.

(4) ONU. Declaração Universal dos Direitos da Criança. Nova York: ONU, 1959. Disponível em: http://www.dhnet.org.br/direitos/sip/onu/c_a/lex41.htm. Acesso: 26 maio. 2016.

(5) BRASIL. Estatuto da Criança e do Adolescente (ECA) - instituído pela Lei no 8.069, de 13 de julho de 1990. Disponível em:

http://www.crianca.mppr.mp.br/arquivos/File/publi/camara/estatuto_crianca_adolesce nte_9ed.pdf . Acesso em: maio. 2016. 